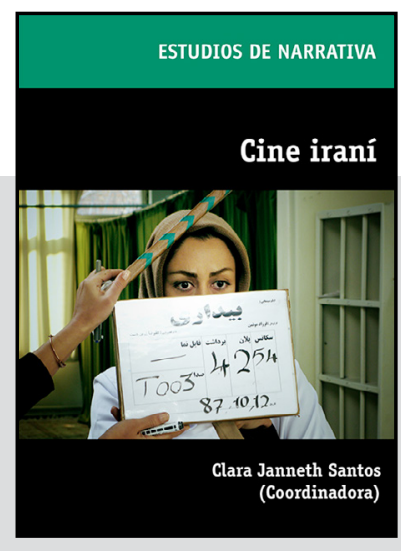

Cine iraní

Clara Janneth Santos (Coord.)

Editorial Icono14, Madrid 2012

\title{
El cine de Irán desde el ámbito académico español
}

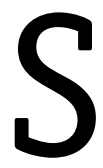

i bien el cine iraní había logrado ocupar un lugar privilegiado dentro del panorama cinematográfico internacional gracias a la irrupción de grandes autores en las principales citas del circuito de festivales de los noventa, su recepción en el mundo editorial español ha sido, cuanto menos, discreta, por el exiguo número de obras científicas que ha generado. A ciertas traducciones se unen escasas monografías en español sobre algunos directores, como la resultante de la tesis doctoral de Farshad Zahedi acerca del realizador Dariush Mehryui. Precisamente el director de esta tesis, el catedrático y prestigioso investigador Alberto Elena, todo un pionero y figura clave en España dentro de los estudios sobre el denominado Tercer Cine, es el encargado de acometer el prólogo de Cine Iraní, volumen colectivo de inequívoco título que, como bien señala él mismo, constituye el primer intento desde el ámbito académico hispánico de tratar una cinematografía tan estimulante como la persa. Bajo la coordinación de Clara Janneth Santos se suceden siete capítulos que revisan de forma accesible la historia cinematográfica iraní y sus principales rasgos definitorios, constituyéndose en una herramienta básica tanto para los que quieran iniciarse como 
para los que, partiendo de los numerosos datos que esta obra aporta, deseen profundizar aún más en el tema.

Los textos inaugurales de Clara Janneth Santos y de Guita Garakâni se destinan al estudio de la historia del séptimo arte en este país de Oriente Medio. Mientras la profesora de la Universidad Autónoma de Bucaramanga vincula su devenir a ciertos episodios históricos, empleando difusamente como marco teórico la sociología del cine de Kracauer o la Semiótica de la Cultura de Iuri Lotman, la investigadora iraní estructura la información estableciendo etapas y proporcionando una importante revisión bibliográfica. Ambas autoras inciden en la perspectiva de género, demostrando que se trata de una cinematografía mucho más plural de lo que en principio podría suponerse. Otros dos apartados se dedican a analizar un par de elementos concretos: la interpretación y las bandas sonoras. Si la actriz Fatemeh Motamed Âria desarrolla muy brevemente el devenir de tres generaciones de actrices que tuvieron que enfrentarse a los contratiempos derivados de la imposición de la ley islámica, la profesora Somayeh Qazizadeh analiza el papel fundamental de la música en la estética persa estableciendo además su canon personal con quince compositores.

Los tres últimos capítulos presentan, desde un punto de vista narratológico y temático, algunas de las cualidades más notables de este cine, vinculándolo además con su tradición cultural. El profesor Farshad Zahedi describe la tipología de personajes realizando un ejercicio comparatista con la literatura y haciendo especial hincapié en la figura del "niño errante". Sobre esta reconocible representación tradicional se centra también el catedrático Francisco García García, llevando a cabo para ello el análisis textual de ¿Dónde está la casa de mi amigo? (Abbas Kiârostami, 1987) y El color del paraíso (Mayid Mayidi, 1999). Mario Rajas, por su parte, trabajará también usando una película como texto, en concreto la exitosa Nader y Simin, una separación (Asqar Farhâdi, 2011), para evidenciar los mecanismos de construcción del melodrama como síntoma de los nuevos derroteros del cine contemporáneo.

Concluiremos señalando que la inclusión de un glosario e información adicional de diversa índole contribuye a cumplir la aspiración de este novedoso libro editado 
por Icono14: constituirse a través de sus 278 páginas no sólo en una guía, sino en el material de referencia ineludible para cualquier investigador que quiera embarcarse en la exploración de esta cinematografía periférica.

Mario de la Torre Espinosa

Universidad de Granada - Universidad de Sevilla

mtorre@ugr.es

DOI: ri14.v12i1.691 | ISSN: 1697-8293 | Año 2014 Volumen 12 N$^{\circ} 1$ | ICONO14 